\title{
An interesting case of small bowel obstruction
}

\section{N Pranesh, K Mainprize}

Answers on $p 630$.

$A^{n}$ 86 year old women presented with a day's history of sudden onset colicky central abdominal pain associated with several episodes of vomiting, some abdominal distension, and an episode of loose stools. She also gave a week's history of dysuria and increased frequency of micturition. Her bowels were previously regular and normal with no history of rectal bleeding. There was no history of anorexia or weight loss. Past history included a right mastectomy and axillary clearance for carcinoma of the breast 11 years previously and a hysterectomy at the age of 29 for postpartum haemorrhage.

On examination her pulse was 88 beats/min, blood pressure 137/58 mm $\mathrm{Hg}$, and temperature $37.7^{\circ} \mathrm{C}$. She was clinically dehydrated and abdominal examination revealed mild distension and lower abdominal tenderness without guarding or rebound tenderness. Bowel sounds were increased and tinkling. The hernial orifices were normal as was digital rectal examination. Examination of the cardiovascular and respiratory systems was also unremarkable.

The initial investigations were as follows: haemoglobin concentration 133 $\mathrm{g} / \mathrm{l}$, white cell count $20.3 \times 10^{9} / \mathrm{l}$, platelet count $243 \times 10^{9} /$, C-reactive protein 122 $\mathrm{mg} / \mathrm{l}$, serum sodium $139 \mathrm{mmol} / \mathrm{l}$, serum potassium $2.8 \mathrm{mmol} / \mathrm{l}$, urea $8.6 \mathrm{mmol} / \mathrm{l}$, creatinine $134 \mathrm{mmol} / \mathrm{l}$. Microscopy of a midstream urine sample revealed 200 pus cells and five red blood cells.
A supine abdominal radiograph (fig 1), an ultrasound scan, and a computed tomogram of the abdomen (fig 2) were requested and suggest the diagnosis.

Despite antibiotic treatment for the confirmed urinary tract infection, she remained unwell and continued to have a distended abdomen with intermittent diarrhoea. She underwent a laparotomy (see fig 3) which confirmed the diagnosis and enabled successful treatment such that the patient made a successful recovery and was discharged home a week later.

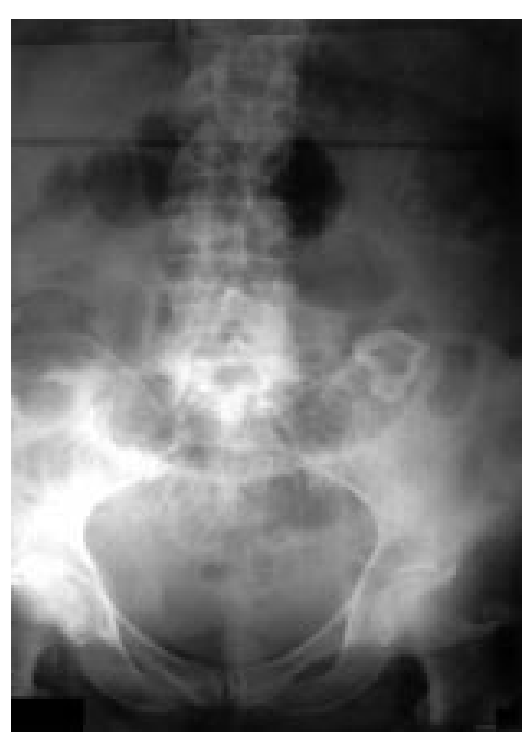

\section{QUESTIONS}

(1) What is the diagnosis?

(2) What is the differential diagnosis?

(3) What are the other possible complications of the primary disease of the small bowel ?

(4) What are the possible treatments options?

Postgrad Med J 2002;78:626

\section{Authors' affiliations}

N Pranesh, K Mainprize, Milton Keynes

General Hospital, Standing Way, Milton

Keynes, Bucks MK6 5LL, UK

Correspondence to: Mr Pranesh; npranesh@hotmail.com

Submitted 27 May 2002

Figure 1 Supine abdominal radiograph. 
Groin pain

\section{latrogenic groin pain}

\section{K Sanyal, A Baneriee}

\section{Answers on $p 630$.}

A 52 year old man presented to the emergency department with progressive left groin pain radiating to the leg. He had attended hospital a week previously with low back pain, at which time no specific diagnosis had been made. There was no history of preceding trauma. The pain was persistent, severe, unrelieved by rest or with analgesics, and interfered with sleep. He was unable to bear weight on the affected limb owing to hip pain and a sensation of weakness. There was no history suggestive of sphincter dysfunction. There were no associated systemic symptoms. It was noted that he was on oral anticoagulation after aortic valve replacement.

On examination, he did not appear toxic. His vital signs were within normal acceptable limits. Tenderness was noted in the left groin, lateral to the femoral arterial pulsation. The left hip was held in slight flexion, and pain was produced on passive extension of the hip. The quadriceps muscle appeared weak, and the knee jerk was diminished. Sensory deficit was noted in the distal anterior thigh and pre-patellar region. There was no evidence of vascular deficit in the lower limb. Examination of the abdomen did not reveal any mass.

Venous blood testing revealed a haemoglobin concentration of $128 \mathrm{~g} / \mathrm{l}$, white cell count $13.2 \times 10 \%$ l, platelet count $186 \times 10^{9} / \mathrm{l}$, sodium $140 \mathrm{mmol} / \mathrm{l}$, potassium $3.5 \mathrm{mmol} / \mathrm{l}$., urea $7.2 \mathrm{mmol} / \mathrm{l}$, glucose $7.9 \mathrm{mmol} / \mathrm{l}$, total protein $74 \mathrm{~g} / \mathrm{l}$, albumin $4 \mathrm{l} \mathrm{g} / \mathrm{l}$, bilirubin $12 \mu \mathrm{mol} / \mathrm{l}$, prothrombin time 7.2 (reference range 1.0-1.3), and partial thromboplastin time $73.0 \mathrm{sec}$ (reference range 25-35).

Computed tomography was carried out (see fig l).

\section{QUESTIONS}

(1) What is the likely clinical diagnosis?

(2) What lesion is shown on the computed tomograms?

(3) How should this condition be managed?

Postgrad Med J 2002;78:627
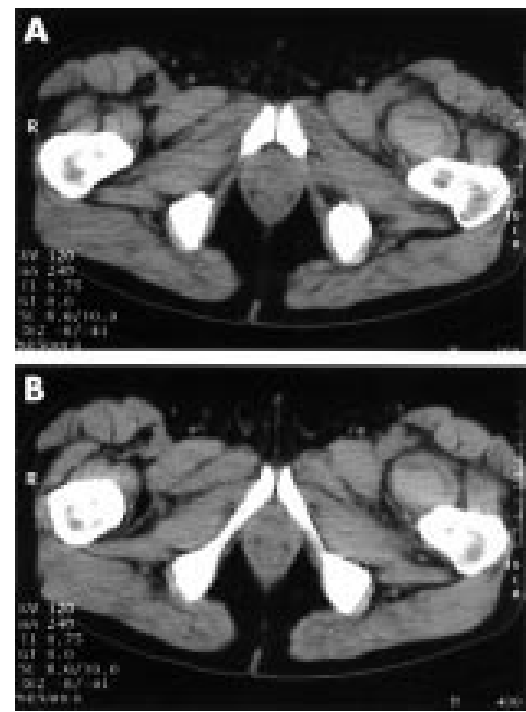

Figure 1 Computed tomograms of patient taken at different levels.

\section{Authors' affiliations}

K Sanyal, A Baneriee, Accident and Emergency Department, Whittington Hospital, Highgate Hill, London N19 5NF, UK

Correspondence to: Mr Banerjee; ashis.banerjee@whittington.nhs.uk

Submitted 11 March 2002

Accepted 29 May 2002

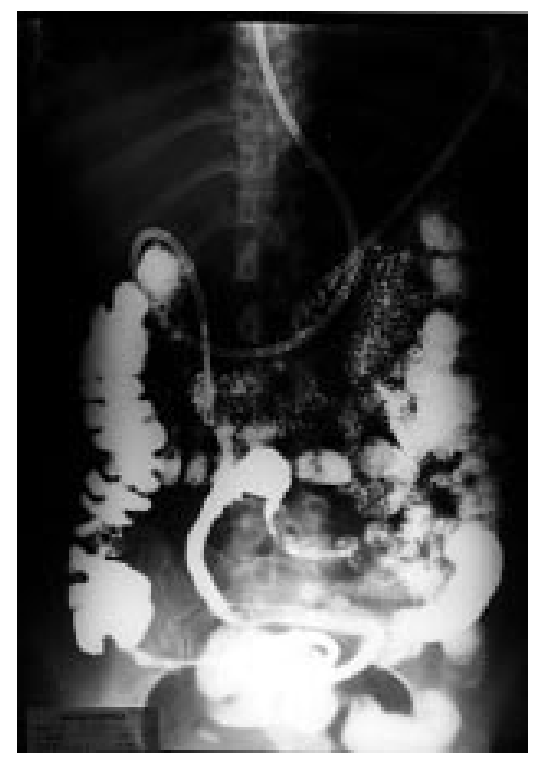

Figure 1 Enteroclysis showing a smooth stricture of the terminal ileum.

Correspondence to: $\operatorname{Dr} \mathrm{V}$ Jayanthi, M 97/5 MIG Flats, Besant Nagar, Chennai 90, India 600 090; drjayant1@vsnl.com

Submitted 10 April 2002

Accepted 11 June 2002 was normal. Computed tomography confirmed thickening of the mesentery and the bowel wall. Terminal ileoscopy and biopsy were non-contributory -

\section{QUESTIONS}

Authors' affiliations

V Jayanthi, Department of Gastroenterology, Stanley Medical College Hospital, Chennai, India

R Girija, GKNM Hospital, Coimbatore, India J F Mayberry, Leicester General Hospital,

Leicester, UK 
Thoracic medicine

\section{Lung nodules in a silver polisher}

\section{S P Bhat, S S Ladhani, J M Joshi}

\section{Answers on $p 631$.}

A 40 year old man, a non-smoker, was referred to us on account of chest radiograph abnormalities that had been discovered during the

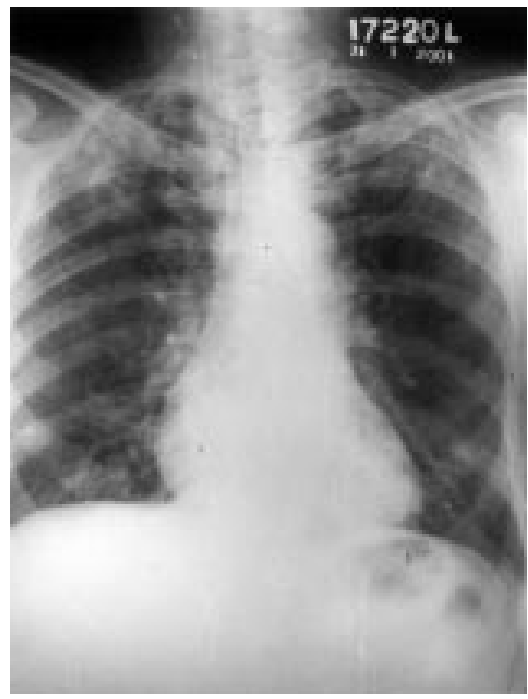

Figure 1 Chest radiograph.

Figure 2 HRCT scan. preoperative evaluation before an Achilles tendon repair. He had no respiratory complaints or significant past medical history. He had been working as a silver polisher for the last 20 years.

His routine blood investigations were normal. The chest radiograph (fig 1) and the high resolution computed tomography (HRCT) lung scan (fig 2) are shown.
Spirometry and arterial blood gases were normal.

\section{QUESTIONS}

(1) What do the chest radiograph and the HRCT of the lung show?

(2) What is the differential diagnosis of the HRCT scan appearance and the likely diagnosis in this case?

Postgrad Med J 2002;78:628

\section{Authors' affiliations}

S P Bhat, S S Ladhani, J M Joshi, T N Medical College and B Y L Nair Charitable Hospital, Dr A L Nair Road, Mumbai 8, India

Correspondence to: Dr Joshi; drioshiim@email.com,

deptrespmed@hathway.com

Submitted 31 December 2001

Accepted 7 May 2002

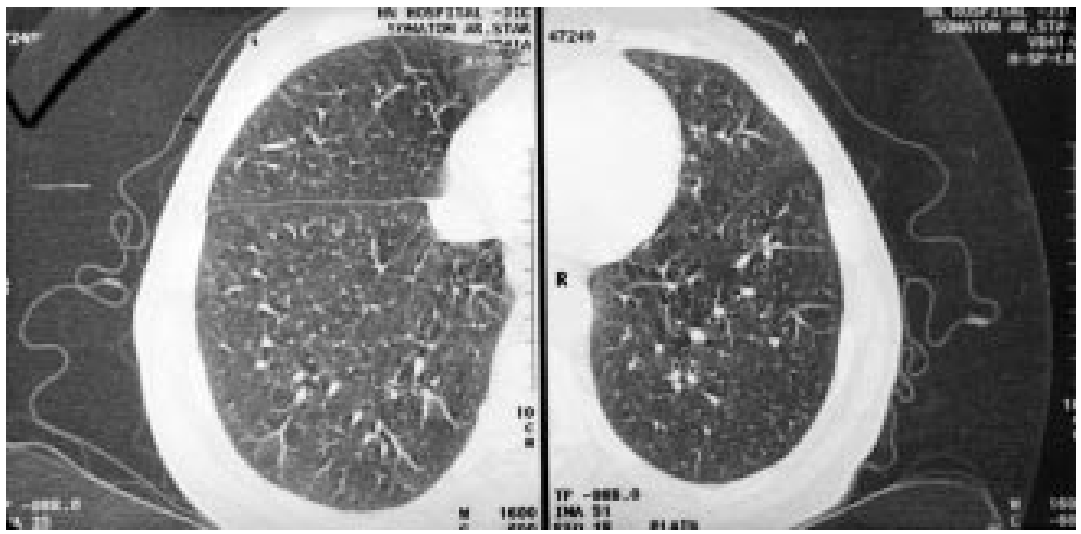

\section{QUESTIONS}

(1) Based on history and clinical examination what is the differential diagnosis?

(2) What are the investigations required? (3) What are the causes of bilateral papilloedema without an expanding intracranial mass lesion?

(4) What are the mechanisms/processes which lead to raised intracranial pressure in patients without intracranial mass lesions?

Postgrad Med J 2002;78:628

Neurological examination in the arms was normal. There was wasting of the right thigh and right leg. The muscle power was grade 4 at right hip and knee and grade 3 at the right ankle. The sensations in right L5-S1 dermatomes were diminished. The right knee and ankle deep tendon reflexes were absent. The plantar response was bilaterally flexor. There were no cerebellar signs. Cranial magnetic resonance imaging showed no cause for raised intracranial pressure and a normal ventricular system.

\section{Authors' affiliations}

S K G Samson, T P Joseph, T Solomon, R T Daniel, C Gnanamuthu, Department of Neurological Sciences, Christian Medical College and Hospital, Vellore, TN 632004, India

Correspondence to: Dr Samson gsskcmc@yahoo.com

Submitted 3 July 2001

Accepted 6 February 2002 
Respiratory medicine

\section{A smoker with an apical mass}

\section{T M O'Connor, M Casey, T Aherne, C P Bredin}

Answers on $p 633$.

A 60 year old woman presented with a two year history of intermittent stabbing pain at her right scapula, radiating to her right upper limb. The pain was increasing in frequency, had no obvious precipitants, and was unaffected by coughing or deep inspiration. She denied dyspnoea, cough, sputum, haemoptysis, or fever. She had smoked 10 cigarettes per day for 20 years.

Physical examination was normal. A chest radiograph (fig 1) demonstrated a

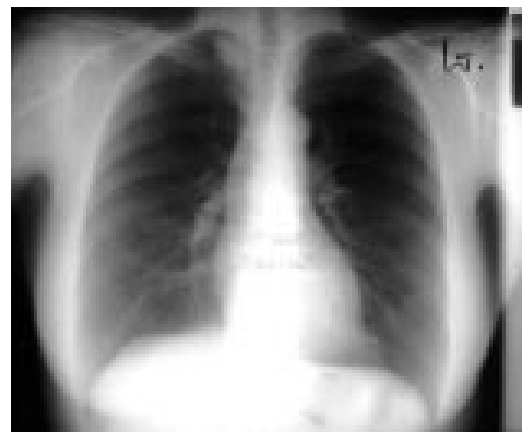

Figure 1 Posteroanterior chest radiograph showing right apical soft tissue mass. well defined soft tissue mass at the right apex. Fibreoptic bronchoscopy was normal. Based on the radiological appearances of the lesion on computed tomography and magnetic resonance imaging (MRI) (figs 2 and 3), a definitive procedure was performed.

\section{QUESTIONS}

(1) Describe the abnormalities shown in figs 2 and 3 .

(2) What is the differential diagnosis?

(3) What was the definitive procedure?

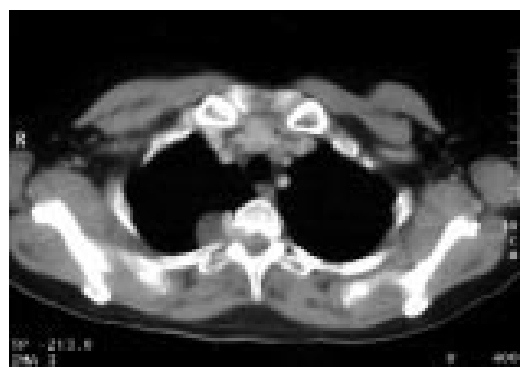

Figure 2 Computed tomogram of chest.
(4) Based on the radiological appearances, what potential complication might arise if the lesion was left untreated?

Postgrad Med J 2002;78:629

\section{Authors' affiliations}

T M O'Connor, C P Bredin, Cork University Hospital, Cork, Ireland: Department of Respiratory Medicine

M Casey, Department of Radiology

T Aherne, Department of Cardiothoracic Surgery

Correspondence to: $\operatorname{Dr} T M O^{\prime}$ Connor, Department of Respiratory Medicine, St Vincent's University Hospital, Elm Park, Dublin 4, Republic of Ireland; terryoconnor@eircom.ne Submitted 10 April 2002

Accepted 27 May 2002

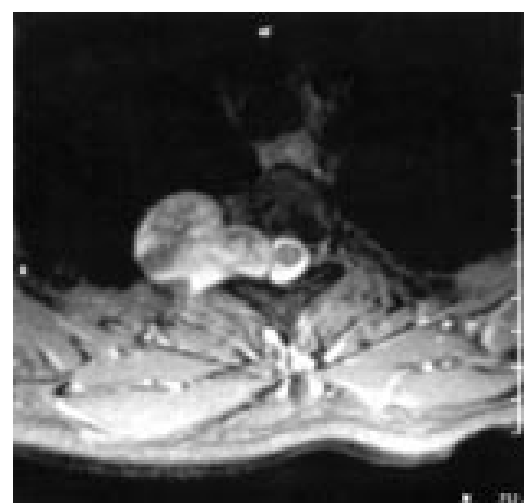

Figure 3 MRI scan.

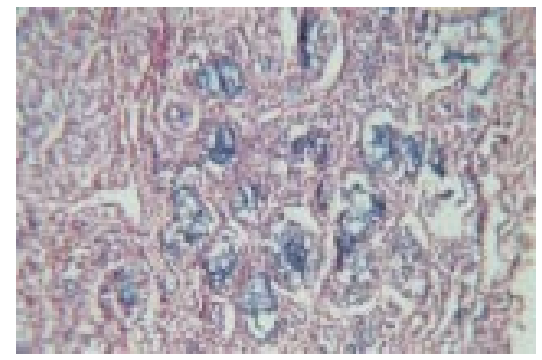

Figure 1 Biopsy specimen.

normal. A chest radiograph showed a soft tissue shadow and on computed tomography there was an erosive lesion over the fifth and sixth rib. Fine needle aspiration from the mass was suggestive of rib secondaries. The patient underwent thoracotomy and rib resection (fig 1).

\section{QUESTIONS}

(1) What is the interpretation of the biopsy specimen?

(2) What are the different types of rib tumours?

(3) What is the mode of spread to the rib? Postgrad Med J 2002;78:629

\section{Authors' affiliations}

V Jayanthi, Coimbatore Medical College Hospital, Coimbatore, India: Department of Gastroenterology

R Vimala, Department of Pathology

Correspondence to: Dr V Jayanthi, M 97/5 600 090; drjayant1@vsnl.com

Submitted 10 April 2002

Accepted 29 July 2002
K Nishal, Department of Medicine MIG Flats, Besant Nagar, Chennai 90, India
Haematological investigations and ultrasonography of the abdomen were 